\title{
Influence of Vestibular Bevel on the Success of Traumatized Teeth Restorations: Single-Blind Randomized Controlled Trial - Preliminary Results with 6-Months Follow-Up
}

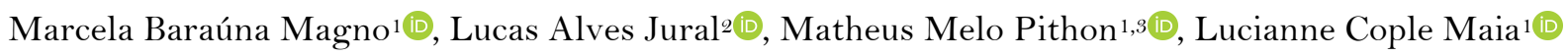

\author{
${ }^{1}$ Department of Pediatric Dentistry and Orthodontics, School of Dentistry, Federal University of Rio de Janeiro, Rio de \\ Janeiro, RJ, Brazil. \\ ${ }^{2}$ School of Dentistry, Federal University of Rio de Janeiro, Rio de Janeiro, RJ, Brazil. \\ ${ }^{3}$ Department of Healthy, School of Dentistry, Southwest Bahia State University, Jequié, Bahia, Brazil.
}

Author to whom correspondence should be addressed: Dra ${ }^{\mathrm{a}}$ Lucianne Cople Maia, Rua Rodolpho Paulo Rocco, 325, Cidade Universitária, Rio de Janeiro, RJ, Brazil.21941-913. Phone: +5521 39382098. E-mail: rorefa@,terra.com.br.

Academic Editor: Alessandro Leite Cavalcanti

Received: 07 February 2020 / Accepted: 23 June 2020 / Published: 06 July 2020

How to cite this article: Magno MB, Jural LA, Pithon MM, Maia LC. Influence of vestibular bevel on the success of traumatized teeth restorations: single-blind randomized controlled trial - preliminary results with 6-months follow-up. Pesqui Bras Odontopediatria Clín Integr. 2020; 20:e0011. https://doi.org/10.1590/pboci.2020.127

\begin{abstract}
Objective: To evaluate the influence of cavosurface vestibular bevel (CSVB) application on the clinical success (CS) of class IV restorations of traumatized permanent teeth, the influence of the number of fracture angles and dental trauma recurrence (DTR) on the restorations retention rate (RRR) and incidence of pulp necrosis (PN). Material and Methods: Fifty-seven children and adolescents with enamel and dentin fractures requiring C-IV restorations were randomly allocated in groups with CSVB and without CSVB. The primary outcomes were the CS of restorations, evaluated using modified USPHS criteria, and the incidence of PN after a 6-months follow-up. As secondary outcomes, the influence of the number of fractured angles and the DTR on the RRR and on the incidence of PN were evaluated (p>0.05). Results: Of 57 children and adolescents, 74 teeth were restored, and 71 completed the six-month follow-up analysis. Teeth restored with and without CSVB displayed similar CS as well as the same incidence of PN ( $\mathrm{p}>0.05)$. The number of fractured angles did not influence the RRR and DTR was not associated with PN ( $>0.05)$. DTR was associated with a lower RRR $(\mathrm{p}<0.001)$. Conclusion: Cavosurface vestibular bevel did not influence the clinical success of Class IV restorations or incidence of PN after 6-months follow-up. DTR did not influence the incidence of pulp necrosis, but did negatively influence the restorations retention rate. The number of fracture angles did not influenced in the restorations retention rate.
\end{abstract}

Keywords: Dental Restoration; Permanent; Dental Restoration Failure; Composite Resin; Tooth Fracture. 


\section{Introduction}

Dental trauma (DT) is a common health problem in the child and adolescent population. The upper incisors being the most frequently involved teeth and enamel and dentin fractures are the most prevalent DT events to occur in these age groups [1]. In cases where fragment bonding cannot be performed, restoration using composite resin is considered the more conservative treatment for teeth with enamel and dentin fractures, requiring minimal dental preparation [2].

The preparation of a vestibular cavosuperficial angle (bevel) has been recommended by in vitro studies to increase the retention of the restoration [3] and to allow a more gradual transition between the restoration and the tooth. However, the influence of this technique on the clinical performance of previous restorations remains debatable [4-6]. Previous authors evaluated the clinical performance of anterior restorations through a systematic review: upon isolating the eight studies that evaluated class IV restorations, it was noticed that the majority of studies were carried out between 1977 and 1997, using many materials that are no longer available on the market and techniques that are not widely in use currently [7]. Besides, none of the included studies evaluated the direct influence of the bevel on restoration clinical performance since they did not adopt the enamel preparation as a single variable to be studied [7].

A previous in vitro study showed that bevel margins on buccal surface of composite restorations reduces marginal leakage when compared to a nonbeveled margins preparation, in primary and permanent teeth [8,9]. Additionally, significant leakage following the path of the dentinal tubules into the pulp could possibly be one of the causes of pulpal inflammation and even pulpal death under restorations [10].

Knowing that the preparation of the vestibular bevel is a routine occurrence in many public and private dental clinics and taking into account the absence of clinical studies that evaluate this variable (enamel bevel), the importance of investigations regarding the impact of cavosurface bevel execution on the clinical performance of class IV restorations is justified.

In this regard, the present randomized clinical trial (RCT) sought to evaluate: (1) the influence of vestibular bevel on clinical success of anterior class IV restorations in teeth that had suffered enamel and dentin fractures; (2) the incidence of pulp necrosis after these restorations comparing teeth that received bevelled margins and nonbevelled margins; (3) the influence of the number of fracture angles on restorations retention rate and the incidence of pulp necrosis; and (4) the influence of DT recurrence on restoration retention rate and the incidence of pulp necrosis. The null hypothesis of this study was that the clinical success and incidence of necrosis of class IV restorations with vestibular bevel application would not be different from those of restorations without vestibular bevel application.

\section{Material and Methods}

\section{Study Design}

The present RCT was registered in the Brazilian Clinical Trials Registry (ReBec) database with the identifier RBR-2pqvv4 and number U1111-1194-7188.

This study was conducted as a prospective, single-blinded clinical RCT [11]. Restorations were performed in 57 children and adolescents (total of 74 teeth) as part of the treatment and monitoring of DT. The parallel model was used and the teeth were randomized and allocated to one of two groups (with and without vestibular bevel application, respectively) (Figure 1). 
A convenience sample was adopted, including all patients with enamel and dentin fractures without pulp exposure [12] who sought treatment at the Dental Trauma Vigilance and Monitoring Center at the Dental School of the Universidade Federal do Rio de Janeiro between November 2016 and December 2018. Patients who met the following inclusion criteria were included: age between seven and 15 years old, having at least one permanent upper anterior tooth (e.g., central incisor, lateral incisor, canine) requiring class IV restoration due to uncomplicated coronary fracture [12] (that could be the first, second, or subsequent, posttrauma restoration), displaying the physical and emotional qualifications to tolerate restorative the procedure, having pulp vitality and accept returning to perform periodic evaluations after restoration procedure.

Patients who suffered other types of trauma to the fractured tooth and/or those with pulpal inflammation or necrosis, previous endodontic treatment, uncontrolled periodontal disease, or parafunctional habits, as well as individuals with special needs and/or motor deficits, were excluded from this study.

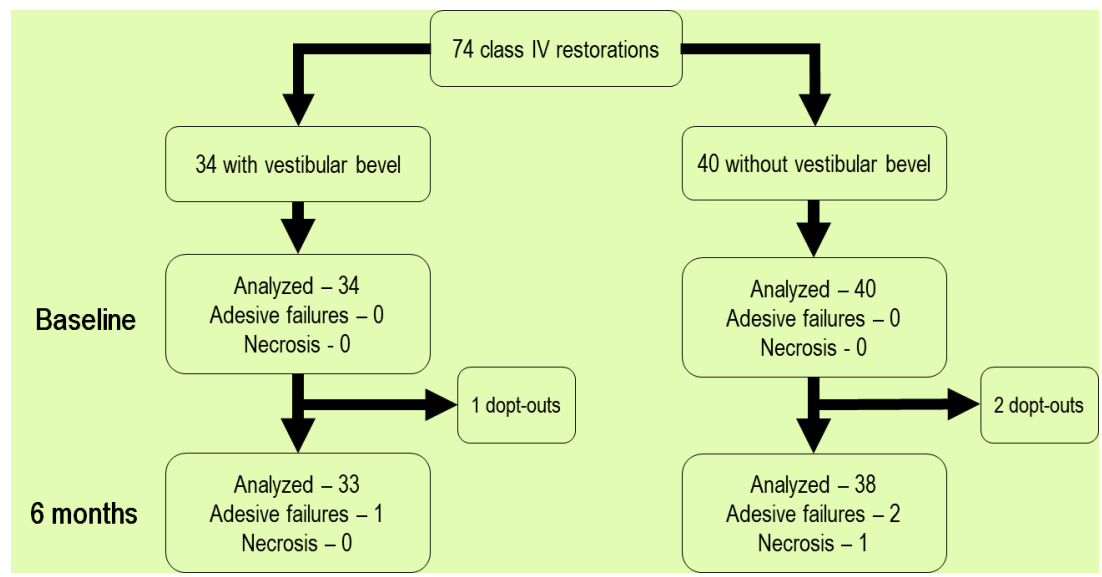

Figure 1. Flow diagram of the trial.

\section{Randomization}

The included teeth were randomized through the order of procedure/technique to avoid any delay in patient care. The type of procedure (i.e., with and without vestibular bevel application) was randomized and predistributed between the two groups, with the aid of the BioEstat 5.0 computer program. This process was performed by an individual blinded to the restoration process and allocation concealment was assured.

A random numbers table was constructed twice: for the first incarnation, a randomization was performed for the first 50 teeth and, when complete, a new randomization was performed for another 50 teeth.

In general, confidentiality was ensured by distributing 100 sequentially numbered white envelopes containing mentions of one of the two groups, following the order of the randomly drawn numbers, totalling 50 envelopes for the control group (without vestibular bevel) and 50 envelopes for the test group (with vestibular bevel). The envelopes were sealed and opaque and the papers with the designated group inside the envelopes were folded to prevent them from being successfully held to a bright light to reveal the contents. The envelopes were opened sequentially and only after the envelope had been irreversibly assigned to a participant.

\section{Restorative Procedure}

A single operator (M. B. M.) performed all restorative procedures. First, the composite resin (Nanofiller Filtek ${ }^{\circledR}$ Z-350; 3M ESPE AG, Seefeld, Germany) shade was selected. Following the administration of local anaesthesia, a rubber dam was placed. If the tooth was allocated to the test group, prior to restoration, 
a bevel in the vestibular tooth surface with a diamond burr (number 1111) at high speed under water-cooling was applied. If the tooth was allocated to the control group, no such preparation was performed. After this step (bevel application or not), the subsequent restorative procedure performed was the same for both groups as follows.

The fractured tooth was cleaned with flour of pumice and water in a rubber cup attached to a lowspeed headpiece. The tooth was then acid-etched with $35 \%$ Scotchbond ${ }^{\circledR}$ Etchant (3M ESPE AG, Seefeld, Germany) for 15 seconds, then thoroughly rinsed for an additional 15 seconds and air-dried prior to the application of the Scotchbond ${ }^{\circledR}$ multipurpose adhesive system (3M ESPE AG, Seefeld, Germany) in accordance with the manufacturer's recommendations. Contour strips (Contour-Strip; Ivoclar Vivadent, Schaan, Liechtenstein) were placed with the help of wedges located interproximally to achieve a smooth restoration outline in the cervical area. The nanofiller Filtek ${ }^{\circledR}$ Z-350 resin composite (3M ESPE AG, Seefeld, Germany) was placed incrementally in 2-mm layers, and each layer was cured for 40 seconds using a light-curing unit. Following removal of the contour strip, the proximal regions of the restorations were additionally polymerized for 20 seconds. Final contouring, finishing, and occlusal adjustments were performed with fine diamond-coated burrs under water-cooling. Occlusion during habitual intercuspidation and excursive movements were checked. One week after restoration, polishing was completed with a four-step polishing disk system (Sof-lex ${ }^{\circledR}$ Pop-on; 3M ESPE AG, Seefeld, Germany) to obtain smooth surfaces. Finally, all patients received orientations to prevent new TD as well as failure of the restorative material and to assure the longevity of the restoration and entered the restoration follow-up period.

\section{Evaluation Procedures}

The restorations were clinically evaluated by two trained and calibrated examiners using a dental explorer and mirror in accordance with modified United States Public Health Service (USPHS) criteria (Table 1) [13]. In this classification criteria, all scores Charlie were considered failures (requiring repair or replacement) and were considered unacceptable. The Kappa interexaminer value was 0.95.

Table 1. United States Public Health Service (USPHS) Ryge Criteria for Direct Clinical Evaluation of Restoration [10].

\begin{tabular}{|c|c|}
\hline Scores & USPHS Criteria \\
\hline \multicolumn{2}{|c|}{ Retention } \\
\hline Alpha (A) & Restoration is intact and fully retained. \\
\hline Bravo (B) & Restoration is partially retained with some portion of the restoration still intact. \\
\hline Charlie $(\mathrm{C})$ & Restoration is completely missing. \\
\hline \multicolumn{2}{|r|}{ Color Match } \\
\hline Alpha (A) & The restoration appears to match the shade and translucency of adjacent tooth tissues. \\
\hline Bravo $(\mathrm{B})$ & $\begin{array}{l}\text { The restoration does not match the shade and translucency of adjacent tooth tissues, but the } \\
\text { mismatch is within the normal range of tooth shades. }\end{array}$ \\
\hline Charlie (C) & $\begin{array}{l}\text { The restoration does not match the shade and translucency of the adjacent tooth structure, and the } \\
\text { mismatch is outside the normal range of tooth shades and translucency. }\end{array}$ \\
\hline \multicolumn{2}{|r|}{ Cavo Surface Marginal Discoloration } \\
\hline Alpha (A) & $\begin{array}{l}\text { There is no visual evidence of marginal discoloration different from the color of the restorative } \\
\text { material and from the color of the adjacent tooth structure. }\end{array}$ \\
\hline Bravo (B) & $\begin{array}{l}\text { There is visual evidence of marginal discoloration at the junction of the tooth structure and the } \\
\text { restoration, but the discoloration has not penetrated along the restoration in a pulpal direction. }\end{array}$ \\
\hline Charlie (C) & $\begin{array}{l}\text { There is visual evidence of marginal discoloration at the junction of the tooth structure and the } \\
\text { restoration that has penetrated along the restoration in a pulpal direction. }\end{array}$ \\
\hline \multicolumn{2}{|r|}{ Anatomic Form } \\
\hline Alpha (A) & $\begin{array}{l}\text { The restoration is a continuation of existing anatomic form or is slightly flattened. It may be } \\
\text { overcontoured. When the side of the explorer is placed tangentially across the restoration, it does }\end{array}$ \\
\hline
\end{tabular}




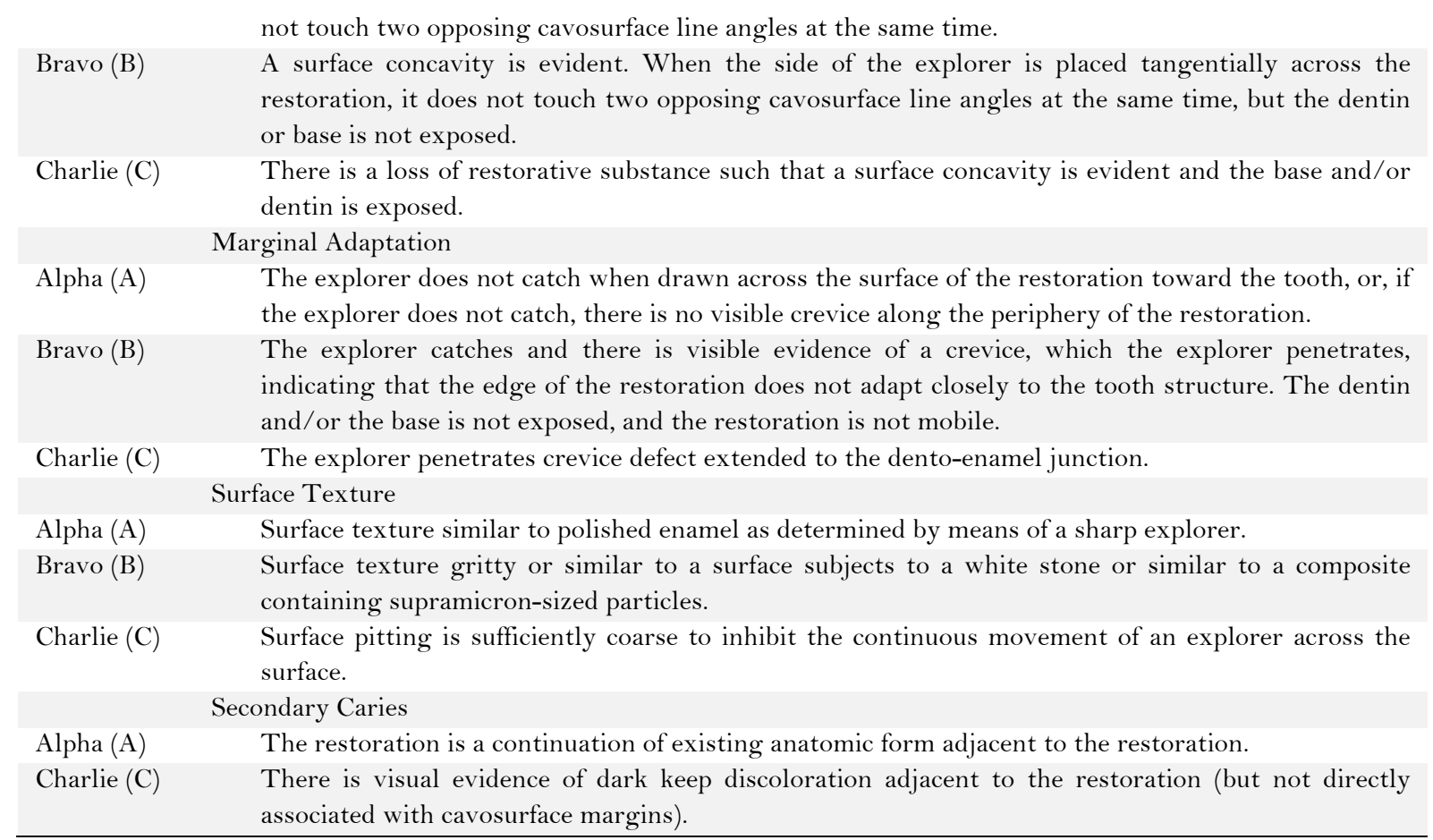

Visual inspection, radiographic examination, and cold vitality test were performed to evaluate the presence of clinical and radiographic signs of pulp necrosis [14] as well as the necessity of endodontic treatment. Where warranted, an evaluation was done to identify the need for endodontic treatment, and those patients who needed this specific treatment were referred to an endodontist. When restorations failed before the baseline clinical evaluation, the date and reasons for failure were recorded in the affected patient's file.

\section{Blinding}

Only the principal investigator performed the clinical research steps. Another calibrated professional evaluator completed the assessment of USPHS parameters, without knowing which treatment was applied, thus ensuring a single-blind study.

\section{Statistical Analysis}

All data were analysed using the SPSS version 20.0 software program (IBM Corp., Armonk, NY, USA). The data for each USPHS criterion were dichotomized according to success or failure as well as the presence or not of vestibular bevel ('yes' or 'no’), DT recurrence ('yes' or 'no’), pulp necrosis ('yes' or 'no’), and number of angles fractured ('one' or 'two' angles). The chi-squared test and t-test for independent variables were used to verify the distribution of characteristics variables of the sample among the groups and differences between the groups. In order to correct the internal correlation of more than one tooth per child, the bootstrap method was applied to construct the bias-corrected accelerated confidence interval with 10.000 resampling. The risk ratio was calculated to evaluate the influence of the vestibular bevel in the retention rate. The level of significance considered for all tests was $5 \%$.

\section{Ethical Aspects}

The present study followed the Consolidated Standards of Reporting Trials (CONSORT) [11] guidelines and was revised and approved by the Research Ethics Committee of Clementino Fraga Filho 
(Universidade Federal do Rio de Janeiro) under the number 1,836,586. At the beginning of the study, all parents and patients were asked to sign a consent form and a patient information sheet, respectively, in full compliance with the Declaration of Helsinki.

\section{Results}

Of the 74 teeth restored, 71 completed the six-month follow-up analysis. The mean age of the children and adolescents included in this study was $9.9 \pm 2.4$ years, and 53 were male $(71.6 \%)$ and 21 were female $(28.4 \%)$. Ultimately, the trial had three drop-outs: two patients (two teeth) did not answer telephone calls and another (one tooth) was excluded due to consecutive absences. Concerning all teeth, the demographic characteristics in each group are described in Table 2 . The number of teeth allocated to the test and control groups, drop-outs, adhesive failures, and necrosis, considering the number of teeth evaluated in the follow-up period, are described in Figure 1.

Table 2. Population distribution between groups in baseline.

\begin{tabular}{|c|c|c|c|}
\hline \multirow{3}{*}{ Variables } & \multicolumn{2}{|c|}{ Vestibular Bevel } & \multirow{3}{*}{ p-value } \\
\hline & Yes & No & \\
\hline & $\mathrm{N}(\%)$ & $\mathrm{N}(\%)$ & \\
\hline \multicolumn{4}{|l|}{ Gender } \\
\hline Female & $13(61.9)$ & $8(38.1)$ & $0.082^{\#}$ \\
\hline Male & $21(39.6)$ & $32(60.4)$ & \\
\hline Age & $10.12 \pm 2.6$ & $9.7 \pm 2.1$ & $0.512^{*}$ \\
\hline \multicolumn{4}{|l|}{ Tooth Type } \\
\hline Central Incisor & $29(44.6)$ & $36(55.4)$ & $0.528^{\#}$ \\
\hline Lateral Incisor & $4(50.0)$ & $4(50.0)$ & \\
\hline Canine & $1(100.0)$ & $0(0.0)$ & \\
\hline \multicolumn{4}{|l|}{ Arch } \\
\hline Maxillary & $30(45.4)$ & $36(54.6)$ & $0.808^{\#}$ \\
\hline Mandibular & $4(50.0)$ & $4(50.0)$ & \\
\hline \multicolumn{4}{|c|}{ Number of Angles Restored } \\
\hline One Angle & $28(45.9)$ & $33(54.1)$ & $0.987^{\#}$ \\
\hline Two Angles & $6(46.1)$ & $7(53.9)$ & \\
\hline \multicolumn{4}{|l|}{ Increased Overjet } \\
\hline Yes & $9(47.4)$ & $10(52.6)$ & $0.723^{\#}$ \\
\hline No & $25(45.5)$ & $30(54.5)$ & \\
\hline \multicolumn{4}{|l|}{ Inadequate Lip Covered } \\
\hline No & $24(41.4)$ & $34(58.6)$ & $0.133^{\#}$ \\
\hline Yes & $10(62.5)$ & $6(37.5)$ & \\
\hline Total & $34(45.9)$ & $40(54.1)$ & \\
\hline
\end{tabular}

Considering the time between DT and patients sought the odontology service, 25 participants (33.7\%) sought care in "up to one month" after DT, 24 (32.4\%) sought care "between 1 and 6 months" after DT and 25 (33.8\%) sought care 6 months after DT.

Clinically, all restored teeth were classified as 'success' for the 'retention' parameter (and could had other parameters evaluated) received scores of A or B at baseline and at six months follow-up for 'colour match', 'cavosurface marginal discoloration', 'anatomic form', 'marginal adaptation', 'surface texture', and 'secondary caries'. Three restorations (4.22\%) presented with adhesive failure (one from the group with vestibular bevel and two from the group without bevel; $\mathrm{p}=0.811)$ and one tooth $(1.4 \%)$ was diagnosed with necrosis (from the group without bevel; $\mathrm{p}=0.582$ ). The number of angles fractured/restored did not influence 
the incidence of adhesive failure ( $p>0.05)$. Adhesive failures and any pulp necrosis diagnoses are described and statistically analysed in Table 3 .

Table 3. Clinical parameters of restored teeth with vestibular bevel (test group) and without vestibular bevel (control group) at baseline and after 6 months of analysis.

\begin{tabular}{|c|c|c|c|c|c|c|c|}
\hline \multirow[t]{2}{*}{ Parameters } & \multirow{2}{*}{$\begin{array}{c}\text { Outcome } \\
\text { assessment }\end{array}$} & \multirow[t]{2}{*}{ Score } & \multicolumn{2}{|c|}{ Baseline } & \multicolumn{2}{|c|}{6 months } & \multirow[b]{2}{*}{$\mathbf{R R}(\mathrm{CI})$} \\
\hline & & & $\begin{array}{l}\text { Test } \\
(\mathrm{n}=34)\end{array}$ & $\begin{array}{l}\text { Control } \\
(\mathrm{n}=40)\end{array}$ & $\begin{array}{c}\text { Test } \\
(\mathrm{n}=33)\end{array}$ & $\begin{array}{c}\text { Control } \\
(\mathrm{n}=38)\end{array}$ & \\
\hline \multirow[t]{3}{*}{ Retention } & Success & Alpha & 34 & 40 & 30 & 36 & $0.57(0.05-6.06)$ \\
\hline & & Bravo & 0 & o & 2 & 0 & \\
\hline & Unsuccess & Charlie & o & o & $1^{\mathrm{a}}$ & $2^{\mathrm{a}}$ & \\
\hline \multirow[t]{3}{*}{ Color Match } & Success & Alpha & 32 & 36 & 30 & 31 & $\mathrm{NA}^{\#}$ \\
\hline & & Bravo & 2 & 4 & 2 & 5 & \\
\hline & Unsuccess & Charlie & o & o & 0 & o & \\
\hline \multirow{3}{*}{$\begin{array}{l}\text { Cavo Surface Marginal } \\
\text { Discoloration }\end{array}$} & Success & Alpha & 34 & 40 & 31 & 34 & $\mathrm{NA}^{\#}$ \\
\hline & & Bravo & o & o & 1 & 2 & \\
\hline & Unsuccess & Charlie & o & o & 0 & $\mathrm{O}$ & \\
\hline \multirow[t]{3}{*}{ Anatomic Form } & Success & Alpha & 34 & 40 & 31 & 33 & $\mathrm{NA}^{\#}$ \\
\hline & & Bravo & o & o & 1 & 3 & \\
\hline & Unsuccess & Charlie & o & o & 0 & o & \\
\hline \multirow[t]{3}{*}{ Marginal Adaptation } & Success & Alpha & 34 & 40 & 23 & 33 & $\mathrm{NA}^{\#}$ \\
\hline & & Bravo & o & o & 9 & 3 & \\
\hline & Unsuccess & Charlie & o & o & 0 & 0 & \\
\hline \multirow[t]{3}{*}{ Surface Texture } & Success & Alpha & 34 & 40 & 32 & 36 & $\mathrm{NA}^{\#}$ \\
\hline & & Bravo & o & 0 & 0 & o & \\
\hline & Unsuccess & Charlie & 0 & o & o & $\mathrm{O}$ & \\
\hline \multirow[t]{2}{*}{ Secondary Caries } & Success & Alpha & 34 & 40 & 33 & 38 & $\mathrm{NA}^{\#}$ \\
\hline & Unsuccess & Charlie & 0 & 0 & 0 & o & \\
\hline \multirow[t]{2}{*}{ Pulpar Condition } & Success & Vitality & 34 & 40 & 33 & 37 & $\mathrm{NA}^{\#}$ \\
\hline & Unsuccess & Necrosis & 0 & 0 & $\mathrm{O}^{\mathrm{a}}$ & $1^{\mathrm{a}}$ & \\
\hline
\end{tabular}

${ }^{a}$ Similar letters demonstrate statistical similarity (p>0.05); RR: Risk Ratio; CI: Confidence Interval; \#NA: Not Applied. Risk ratio could not be calculated since the number of events (restorations unsuccess) were o (zero) in test and/or control group.

Of the total number of adhesive failure restorations $(\mathrm{n}=3), 100 \%$ occurred due to DT recurrence $(\mathrm{p}<0.001)$. There was no association between pulp necrosis and the recurrence of DT $(\mathrm{p}=0.915)$.

\section{Discussion}

The concepts and techniques of dental preparation must evolve with the advance of composite and adhesive restorative systems, with attention paid to the current popular concept of minimally invasive operation [15]. This approach is especially relevant in young patients since it is perhaps more likely that restoration replacement will occur during their lives due to the anticipated greater length of such [4]. The initial composite restoration should be as conservative as possible to minimize the costs and complexity of any replacement restoration. However, besides preserving the dental remnant, it is necessary that these restorations present a good clinical performance without the occurrence of pulp lesions.

To our knowledge, the present study is the first RCT to directly evaluate the influence of vestibular bevel in class IV restorations. Ultimately, our null hypothesis was confirmed and preliminary results showed that applying a vestibular bevel in class IV teeth did not influence the clinical performance of the restorations or impact the pulp vitality of the teeth.

Although the total number of adhesive failures in the present RCT was low (4.2\%), it is in accordance with the finding of Demarco et al. [16], who reported that fracture of tooth/restoration was the most common reason for failure. Elsewhere, it was suggested that all composite restorations in traumatically damaged teeth 
need to be replaced after three to five years of restorative procedure, representing a reason for why these restorations should be followed up with during at least this period [Q]. However, different from the present RCT, previous author included teeth both with and without pulp exposure, and the differences in inclusion criteria and follow-up period could explain this divergence [Q].

Although in vitro studies have reported that enamel bevel application increased the fracture resistance of direct composite resins [3,17], in the present RCT, the vestibular bevel did not influence the retention rate of restorations of uncomplicated enamel/dentine class IV fractures. It must be taken into account that, in the oral environment, tooth restorations are constantly subject to physical (e.g., abrasion, chewing, functional habits) and chemical (e.g., biofilm, humid environment, erosive and dietary products) challenges in a combined and routine manner, so the results of in vitro studies were not confirmed in the present RCT. Furthermore, all restoration failures were due to DT recurrence, meaning that the forces exerted on a tooth during DT should be considered a sufficient factor to break the tooth during an original episode of DT and the class IV adhesive restoration in cases of DT recurrence.

In the present study, the rate of bond degradation, characterized by a further increase in the presence of small but clinically acceptable marginal defects and superficial marginal discoloration [13], was similar in both groups. Previous studies have reported that these failure parameters take longer to appear in adhesive restorations completed with etch-and-rinse adhesives [18,19]. In the present RCT, a three-step etch-and-rinse adhesive system was used in all restorations. Perhaps use of a different adhesive system could influence marginal adaptation and marginal discolorations to a different degree than a vestibular bevel, and the choice and the use of Scotchbond ${ }^{\mathrm{TM}}$ multipurpose could influenced in none failure due marginal adaptation and discoloration failures. At this time, the literature lacks studies that elucidate these questions.

Colour match and surface texture are parameters that potentially depend more on the brand of the composite resin and polishing system used [20] than on the presence or not of a vestibular bevel, while the anatomical form is may be dependent more on the manual skills of the operator. The similarities observed between groups could be explained because the composite resin, polishing system, and operator were the same for all restorations performed.

The incidence of caries adjacent to the restorations was null for both groups. This result agrees with a previous systematic review that reported a low frequency $(2.5 \%)$ of caries after 10 years in class III and IV restorations [7]. This study also reported that this outcome was not related with the type of composite resin, enamel and dentin conditioning, or bevelling of the cavity, but was associated with the absence of a rubber dam during the restoration procedure [7]. Since all of the restorations in the present study involved a rubber dam, this potential complicating factor was eliminated.

Only one tooth was diagnosed with pulp necrosis (1.4\%) in the present research. Previous studies have reported the incidence of pulp necrosis in anterior restoration teeth ranges from $4.88 \%$ [21] to $22.7 \%$ [22]. The pulp necrosis of restored teeth could be related to the pulp response due to marginal infiltration [10]. Maybe, the presence of vestibular bevel could reduce the incidence of marginal infiltration [8, 9]. However, it must be taken into account that, different from these other studies [21,22], in the present RCT, the participants were followed only for six months, and the incidence of pulp necrosis could easily increase over time.

The number of angles involved in restorations did not influence the retention rate of the restorations in the present RCT. Previous studies have found that any decrease in adhesive toughness appears to be independent of dentin tubule orientation [23,24]. Changes in the fracture toughness may be related to 
dehydration [25], an increase in the degree of crosslinking of the collagen fibrils [26], or a rise in the degree of tubule mineralization with age [27]. More studies evaluating this subject are necessary to provide better clarification since other factors related to the area exposed for treatment and the force dissipation could also have an influence.

Although all patients received orientations to avoid DT recurrence, the incidence of restoration fracture due to new DT episodes was high (100\% of those that experienced retention failure) in the present RCT. This could be explained by the fact that individuals with a previous DT history present a greater risk for DT recurrence [28], increasing the rate of restoration failure in the present study. Considering this, patients should be evaluated individually and not only considering DT itself, and the risk factors associated with this occurrence (i.e., anatomical, physical, behavioural, environmental, and health-related factors that can predispose children to DT) should be identified and treated and/or discussed about so as to avoid future DT. The authors want to highlight that, during the present RCT, the patients did not receive any orthodontic treatment; however, at the end of the six-month follow-up period, all patients were referred for orthodontic treatment, if necessary.

The present RCT adopted a convenience sample and presented only six months of follow-up. These aspects could be considered as study limitations. However, it similarly needs to be considered that all patients with enamel and dentin crown fractures without pulp exposition that sought treatment at a DT reference centre during two years were included in the present study. Additional recall visits are planned to verify the clinical performance of these restoration procedures over time.

\section{Conclusion}

The present RCT showed that application of a cavosurface vestibular bevel did not significantly influence the clinical performance of class IV restorations and incidence of pulp necrosis at six months after restorations. DT recurrence did not influence the incidence of pulp necrosis but negatively influenced the retention rate.

\section{Authors' Contributions}

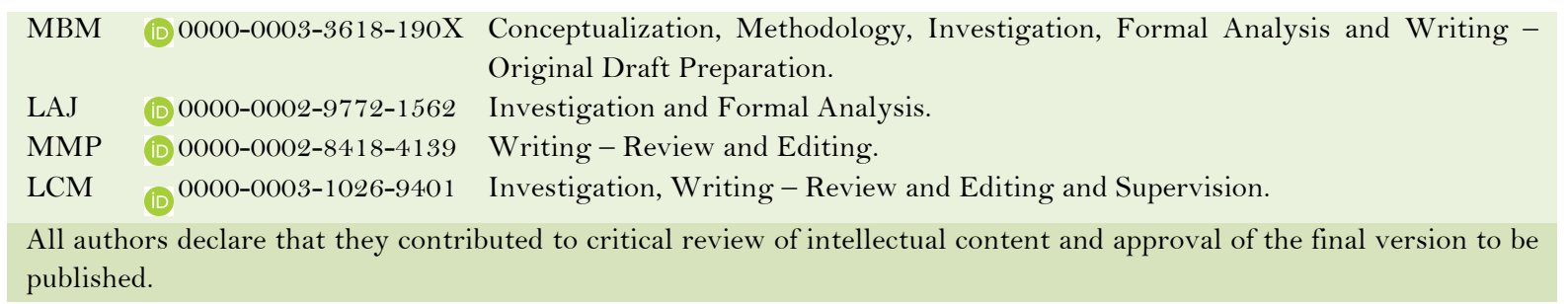

\section{Financial Support}

Foundation for Research Support of the State of Rio de Janeiro (Grants No. E-26/202.333/2019, E-26/202.334/2019 and E-26/010.100992/2018).

\section{Conflict of Interest}

The authors declare no conflicts of interest.

\section{References}


[1] Azami-Aghdash S, Ebadifard Azar F, Pournaghi Azar F, Rezapour A, Moradi-Joo M, Moosavi A, et al. Prevalence, etiology, and types of dental trauma in children and adolescents: systematic review and meta-analysis. Med J Islam Repub Iran 2015; 29(4):234.

[2] Spinas E. Longevity of composite restorations of traumatically injured teeth. Am J Dent 2004; 17(6):407-11.

[3] Xu H, Jiang Z, Xiao X, Fu J, Su Q. Influence of cavity design on the biomechanics of direct composite resin restorations in Class IV preparations. Eur J Oral Sci 2012; 120(2):161-7. https://doi.org/10.1111/j.1600-0722.2012.00943.x

[4] Baratieri LN, Ritter AV. Critical appraisal. To bevel or not in anterior composites. J Esthet Restor Dent 2005; 17(4):264-9. https://doi.org/10.1111/j.1708-8240.2005.tb00126.x

[5] Schroeder M, Reis A, Luque-Martinez I, Loguercio AD, Masterson D, Maia LC. Effect of enamel bevel on retention of cervical composite resin restorations: a systematic review and meta-analysis. J Dent 2015; 43(7):777-88. https://doi.org/10.1016/j.jdent.2015.02.017

[6] Stellini E, Stomaci D, Stomaci M, Petrone N, Favero L. Fracture strength of tooth fragment reattachments with postpone bevel and overcontour reconstruction. Dent Traumatol 2008; 24(3):283-8. https://doi.org/10.1111/j.1600-9657.2007.00539.x

[7] Heintze SD, Rousson V, Hickel R. Clinical effectiveness of direct anterior restorations - a meta-analysis. Dent Mater 2015; 31(5):481-95. https://doi.org/10.1016/j.dental.2015.01.015

[8] Coutinho TCL, Tostes MA. Comparison of microleakage of different margin types around Class V resin restorations in primary teeth. Eur J Paediatr Dent 2013; 14(3):246-51.

[9] Swanson TK, Feigal RJ, Tantbirojn D, Hodges JS. Effect of adhesive systems and bevel on enamel margin integrity in primary and permanent teeth. Pediatr Dent 2008; 30(2):134-40.

[10] Goldman M, Laosonthorn P, White RR. Microleakage - full crowns and the dental pulp. J Endod 1992; 18(10):473-5. https://doi.org/10.1016/Soo99-2399(06)81345-2

[11] Schulz KF, Altman DG, Moher D, CONSORT Group. CONSORT 2010 statement: updated guidelines for reporting parallel group randomised trials. PLoS Med 2010; 7(3):e1000251. https://doi.org/10.1371/journal.pmed.1000251

[12] Andrasen JO, Andreasen FM, Andersson L. Textbook and Color Atlas of Traumatic Injuries to the Teeth. 5th ed. London: Wiley-Blackwell; 2018. 1064 p.

[13] Cvar JF, Ryge G. Reprint of criteria for the clinical evaluation of dental restorative materials. 1971. Clin Oral Investig 2005; 9(4):2 15-32. https://doi.org/10.1007/s00784-005-0018-z

[14] Diangelis AJ, Andreasen JO, Ebeleseder KA, Kenny DJ, Trope M, Sigurdsson A, et al. Guidelines for the management of traumatic dental injuries: 1. Fractures and luxations of permanent teeth. Pediatr Dent 2016; 38(6):358-68. https://doi.org/10.1111/j.1600-9657.2011.01103.x

[15] Mackenzie L, Banerjee A. Minimally invasive direct restorations: a practical guide. Br Dent J 2017; 223(3):163-71. https://doi.org/10.1038/sj.bdj.2017.661

[16] Demarco FF, Collares K, Coelho-de-Souza FH, Correa MB, Cenci MS, Moraes RR, et al. Anterior composite restorations: A systematic review on long-term survival and reasons for failure. Dent Mater 2015; 31(10):1214-24. https://doi.org/10.1016/j.dental.2015.07.005

[17] Coelho-de-Souza FH, Camacho GB, Demarco FF, Powers JM. Influence of restorative technique, beveling, and aging on composite bonding to sectioned incisal edges. J Adhes Dent 2008; 10(2):113-7.

[18] Kubo S, Kawasaki K, Yokota H, Hayashi Y. Five-year clinical evaluation of two adhesive systems in non-carious cervical lesions. J Dent 2006; 34(2):97-105. https://doi.org/10.1016/j.jdent.2005.04.003

[19] Peumans M, De Munck J, Van Landuyt KL, Poitevin A, Lambrechts P, Van Meerbeek B. A 13-year clinical evaluation of two three-step etch-and-rinse adhesives in non-carious class-V lesions. Clin Oral Investig 2012; 16(1):129-37. https://doi.org/10.1007/s00784-010-0481-z

[20] Gönülol N, Yilmaz F. The effects of finishing and polishing techniques on surface roughness and color stability of nanocomposites. J Dent 2012; 40(Suppl 2):e64-70. https://doi.org/10.1016/j.jdent.2012.07.005

[21] Viduskalne I, Care R. Analysis of the crown fractures and factors affecting pulp survival due to dental trauma. Stomatologija 2010; 12(4):109-15.

[22] Guan Y, Qin M. A retrospective study of 415 uncomplicated crown-fracture teeth. Hua Xi Kou Qiang Yi Xue Za Zhi 2008; 26(5):516-8.

[23] Koester KJ, Ager 3rd JW, Ritchie RO. The effect of aging on crack-growth resistance and toughening mechanisms in human dentin. Biomaterials 2008; 29(10):1318-28. https://doi.org/10.1016/j.biomaterials.2007.12.008

[24] Nazari A, Bajaj D, Zhang D, Romberg E, Arola D. Aging and the reduction in fracture toughness of human dentin. J Mech Behav Biomed Mater 2009; 2(5):550-9. https://doi.org/10.1016/j.jmbbm.2009.01.008

[25] Toto PD, Kastelic EF, Duyvejonck KJ, Rapp GW. Effect of age on water content in human teeth. J Dent Res 1971; 50(2):1284-5. https://doi.org/10.1177/00220345710500053201

[26] Miura J, Nishikawa K, Kubo M, Fukushima S, Hashimoto M, Takeshige F, et al. Accumulation of advanced glycation end-products in human dentine. Arch Oral Biol 2014; 59(2):119-24. https://doi.org/10.1016/j.archoralbio.2013.10.012 
[27] Porter AE, Nalla RK, Minor A, Jinschek JR, Kisielowski C, Radmilovic V, et al. A transmission electron microscopy study of mineralization in age-induced transparent dentin. Biomaterials 2005; 26(36):7650-60. https://doi.org/10.1016/j.biomaterials.2005.05.059

[28] Magno MB, Neves AB, Ferreira DM, Pithon MM, Maia LC. The relationship of previous dental trauma with new cases of dental trauma. A systematic review and meta-analysis. Dent Traumatol 2019; 35(1):3-14. https://doi.org/10.1111/edt.12449 